\title{
Water Vapor Permeation through Cellulose Acetate Membranes and Its Impact upon Membrane Separation Performance for Natural Gas Purification
}

\author{
George Q. Chen ${ }^{1}$, Shinji Kanehashi ${ }^{1}$, Cara M. Doherty ${ }^{2}$, Anita J. Hill ${ }^{2}$, Sandra E. Kentish ${ }^{1 *}$ \\ ${ }^{1}$ Co-operative Research Centre for Greenhouse Gas Technologies (CO2CRC), Department of \\ Chemical and Biomolecular Engineering, University of Melbourne, Victoria 3010, Australia. \\ ${ }^{2}$ CSIRO Manufacturing, Clayton South MDC, VIC 3169, Australia
}

Keywords: Water vapor; Carbon dioxide; Methane; Cellulose acetate; Natural gas; plasticisation

${ }^{*}$ Corresponding Author

Tel: +613 83446682

Fax: +61 383444153

E-mail address: sandraek@unimelb.edu.au 


\section{ABSTRACT}

Cellulose acetate is the predominant material used in membrane separation of acid gases from natural gas and biogas. However, while these membranes have been used for decades, the sensitivity of their separation performance to water vapor is not well understood. In this work, flat-sheet membranes fabricated from two types of cellulose acetate of different degrees of acetylation, were exposed to both dry and humidified $\mathrm{CH}_{4}$ and $\mathrm{CO}_{2} / \mathrm{CH}_{4}$ mixtures over a wide range of water activities. Positron Annihilation Lifetime Spectroscopy experiments showed that the number of free volume elements decreased as water concentration increased, indicating pore filling effects. The size of the free volume elements declined initially, followed by an increasing trend at vapor partial pressures greater than $2.5 \mathrm{kPa}$, indicating polymer swelling. Gas permeabilities of $\mathrm{CH}_{4}$ and $\mathrm{CO}_{2}$ followed a similar trend, with an initial decline due to hindered diffusion and competitive sorption, followed by an increase as the humidity exceeded $2.5 \mathrm{kPa}$. Water vapor permeabilities increased continuously from 11,000 to 27,000 Barrer as the water activity increased but a change in the rate of increase was also noted at $2.5 \mathrm{kPa}$. At humidities in excess of 0.8 , the extent of membrane swelling was such that equilibrium was not established even after 8 hours of operation. Importantly, plasticisation had significantly less impact on the polymer with a higher degree of acetylation and for this polymer, water partial pressures of up to $2.5 \mathrm{kPa}$ could be readily tolerated within a comparable industrial operation for extended periods. 


\section{INTRODUCTION}

Natural gas production is estimated to be over 3300 billion cubic metres per year worldwide [1] and the removal of acid gases from the raw gas is the largest industrial market for membrane gas separation. While the composition of raw natural gas is different from reservoir to reservoir, it primarily consists of methane (70-90\%), with small amounts of $\mathrm{C}_{1}-\mathrm{C}_{4}$ hydrocarbons such as ethane, propane, butane, along with higher molecular weight fractions. Water vapor, carbon dioxide, acidic gases, mercury, hydrogen sulfide, helium and nitrogen are also present in raw natural gas as impurities. A glycol dehydration unit is typically used for removing water from the natural gas feed streams prior to membrane processing [2]. However, some water vapor may still reach the membrane if the glycol unit is not working effectively. Further, glycol units are not always used is smaller installations such as biogas processing.

Cellulose acetate was the original membrane material used for $\mathrm{CO}_{2}$ separation from natural gas, building on the experience gained using this material for the desalination of saline water. Cynara ${ }^{\circledR}$ (part of Cameron) and UOP Separex ${ }^{\circledR}$ (part of Honeywell) are the two major membrane manufacturers currently supplying cellulose acetate based modules. Depending on the degree of acetylation, which corresponds to the extent of substitution of the hydroxyl groups in the glucoside repeating unit with acetyl groups (Figure 1), the polymer is named as cellulose acetate, cellulose diacetate or cellulose triacetate.

Dehydration units (mostly diethylene or triethylene glycol dehydrators) are widely used upstream of the membrane unit to prevent hydrate formation [3], typically reducing the water content to $\sim 100 \mathrm{ppm}$ at around $70 \mathrm{bar}, 60^{\circ} \mathrm{C}$ [4]. It has previously been reported that the presence of water and some hydrocarbon derivatives (e.g. acetone) can damage and dissolve the membrane [5], but the sensitivity of the separation performance of cellulose acetate membranes to water vapor is not well understood. Almost all studies on the effects of water vapor on cellulose acetate membranes were conducted in the 1980s [5-9]. The permeation measurements in this period often assumed ideal mixing of water vapor and gas and neglected the impact of concentration polarization upon the permeation properties.

Due to its small size and high hydrogen bonding affinity [10-12], water vapor can have a very significant effect upon membrane performance [7, 13-15]. It is argued that the clustering of water into multimolecular groups can act to 'fill' the free volume within the polymer structure, resulting in a loss of fractional free volume $[16,17]$. It has been reported that these water clusters result in a decrease in the penetrant diffusivity as water vapor activity increases in a phenomenon referred to as 'antiplasticisation' [18-24]. Conversely, water molecules can 
plasticize or swell the membrane structure, causing an increase in free volume and a corresponding increase in diffusivity with increasing vapor concentration [25-28]. Depending on the hydrophobicity of the membrane and the activity of water vapor, these phenomena may coexist in a multi-component separation system, in both cases causing a loss of selectivity.

In this work., the mixed vapor/gas permeation system developed within our group to eliminate concentration polarization effects [15] combined with Positron Annihilation Lifetime Spectroscopy (PALS) [29] is applied to quantify the permeation of water/ $\mathrm{CO}_{2}$ mixtures through cellulose acetate membranes more accurately, allowing for a better understanding of the behavior of water vapor in a simulated natural gas sweetening environment. Two types of cellulose acetate with different degree of acetylation are investigated during exposure to humidified methane and wetted carbon dioxide and methane mixtures.

\section{EXPERIMENTAL}

\subsection{Materials}

Cellulose acetate with acetylation degrees of 51.6\% (CDA) and 61.6\% (CTA) (equivalent to degrees of substitution of 2.2 and 2.85 respectively) were kindly supplied by Daicel Corporation, Japan, in a powder state. The chemical structure of a typical cellulose acetate is presented in Figure 1. Prior to membrane fabrication, the polymers were dried at $100^{\circ} \mathrm{C}$ under vacuum overnight to ensure the complete removal of moisture.

Figure 1

\subsection{Membrane preparation}

Dense cellulose acetate membranes were prepared by a casting method using dichloromethane (DCM, Analytical reagent, Chem-Supply, Australia) for CTA and tetrahydrofuran (THF, Analytical reagent, Chem-Supply, Australia) for CDA. The casting solution (1 wt\%) was filtered into glass petri dishes. The petri dishes were covered and left to dry at room temperature for 24 hours. The homogeneous membranes were then removed from the petri dishes using a small amount of distilled water and dried under vacuum at $35^{\circ} \mathrm{C}$ for 24 hours, followed by $100^{\circ} \mathrm{C}$ for 24 hours to remove the residual solvent. The dried membranes were kept in a desiccator to prevent any subsequent absorption of atmospheric moisture. Membrane thicknesses for the dense flat sheet films were determined from the 
mean value of at least 40 locations across the film using a micrometer (Mitutoyo, Japan) and varied from 50 to $60 \mu \mathrm{m}$. Typically the thickness variation within a sample was less than 8 microns.

\subsection{Characterization}

The buoyancy technique is a standard displacement technique for measuring membrane densities and is adopted widely in the literature [30-32]. A well-dried membrane was weighed in air $\left(w_{\text {air }}\right)$, then in hexane (AR, Chem-Supply, Australia) $\left(w_{\text {Hexane }}\right)$ using an analytical balance (Mettler Toledo AB204-5). The density of the polymer membrane ( $\rho_{\text {polymer }}$ ) was calculated using the hexane density $\left(\rho_{\text {Hexane }}\right)$ via the following equation:

$$
\rho_{\text {polymer }}=\left(\frac{w_{\text {air }}}{w_{\text {air }}-w_{\text {Hexane }}}\right) \rho_{\text {Hexane }}
$$

The mass uptake of water was determined by immersing the membrane sample in pure water at $35^{\circ} \mathrm{C}$ for at least 3 days, to ensure that water sorption equilibrium was attained. The water uptake was calculated from:

$$
\text { Water uptake }=\frac{w_{\text {wet }}-w_{d r y}}{w_{d r y}} \times 100
$$

where $w_{\text {wet }}$ and $w_{\text {dry }}$ are the weight of a water-swollen membrane at equilibrium state and dry state respectively.

The dry and wetted membranes, prepared in the same way as for the water uptake experiment, were measured using Wide-angle X-ray diffraction (WAXD). The measurements were performed on a D8 Advance X-ray diffractometer (Bruker, Germany) at 5 seconds per step of $0.02^{\circ}$, using a Ni-filtered CuKa radiation source at $40 \mathrm{kV}$ and $30 \mathrm{~mA}$. The samples were analyzed over a range of $3^{\circ}$ and $30^{\circ}$. The mean d-spacing, which represents the mean distance between polymer chains, was calculated using Bragg's equation:

$$
\lambda=2 d \sin \theta
$$

where $\lambda$ is the wavelength of the radiation, $1.54 \AA$, and $2 \theta$ the maximum intensity in a halo peak. The degree of crystallinity was determined based on the percentage of the crystalline area in the XRD profile using the deconvolution method [33].

The free volume distribution of the membrane samples over a range of vapor activities was determined using positron annihilation lifetime spectroscopy (PALS) at ambient temperature. Positrons are emitted from a radioactive isotope source $\left({ }^{22} \mathrm{NaCl}\right)$ and enter into the 
surrounding sample. The positrons are thermalised via inelastic collisions within the samples and are either annihilated as free positrons in the bulk of the membrane or became trapped in micro-pores or regions of lower than average electron density. A positron forming a bound state with an electron of opposite spin (para-positronium) has the shortest lifetime $\left(\mathrm{T}_{1}, \sim 125 \mathrm{ps}\right)$, whereas localisation of the positrons in the bulk of the material (areas abundant in electrons) results in annihilation at around $\mathrm{T}_{2} \sim 300-500 \mathrm{ps}$. The third component ( $\mathrm{T} 3$ ), ortho-positronium (positron and electron in a bound state of the same spin) will sit in electron deficient regions, such as pores or voids and will lead to more protracted lifetimes ( $<142 \mathrm{~ns}$ ). This component can provide information on the size of the free volume cavities or micropores within the sample. The intensity of the ortho-positronium (OPs), I3, is related to the relative concentration of free volume sites. The size of the pores can be calculated using a semi-empirical equation using the quantum mechanical model of Tao and Eldrup [34] based on the mean lifetime for ortho-positronium, where $R$ is the diameter of the cavity and $\Delta R$ was determined to be 1.656 Aิ.

$$
\tau_{3}=0.5 \times\left[1-\frac{R}{R+\Delta R}+\frac{1}{2 \pi} \sin \left(\frac{2 \pi R}{R+\Delta R}\right)\right]^{-1}
$$

As described in a previous publication [35], PALS experiments were performed using an EG\&G Ortec fast-fast coincidence system with fast plastic scintillators and a resolution function of 260 ps FWHM (Determined using a 60Co source with the energy windows set to $22 \mathrm{Na}$ events). Approximately $2 \mathrm{~mm}$ of sample was stacked on either side of a $30 \mu \mathrm{Ci}{ }^{22} \mathrm{NaCl}$ positron source sealed between $2.54 \mu \mathrm{m}$ Mylar films. The samples were measured at room temperature in a humidity controlled environment which was adjusted by mixing saturated and dry $\mathrm{N}_{2}$ streams. The spectra were collected at each humidity level until the lifetime and intensity measurements had stabilised. Once the samples had equilibrated, a minimum of five spectra of 1 million integrated counts were collected for each sample. Data analysis was performed using LT9 software [36] using a source correction of 1.921 ns and $3.618 \%$. The spectra were fitted with three components for the membrane samples.

\subsection{Vapor/gas permeation measurements}

A mixed vapor/gas permeation set-up developed in an earlier publication [15] was used for measuring the permeabilities of water vapor and gas mixtures. All permeation measurements were conducted at $35^{\circ} \mathrm{C}, 7.5$ bar. At equilibrium conditions, relative humidity can be related to water activity $\left(a_{w}\right)$ :

$$
a_{w}=\frac{R H}{100}=\frac{P_{\mathrm{H}_{2} \mathrm{O}}}{P_{\text {sat }}}
$$


where $P_{\mathrm{H}_{2} \mathrm{O}}$ is the water vapor partial pressure and $P_{\text {sat }}$ the saturation water vapor pressure $\left(5.78 \mathrm{kPa}\right.$ at $\left.35^{\circ} \mathrm{C}\right)$.

\section{RESULTS AND DISCUSSION}

\subsection{Characterization}

The physical properties of the cellulose acetate membranes are summarized in Table 1. CDA is more dense than CTA due to both the more bulky nature of the acetyl groups, which result in greater free volume as the acetylation degree increases; and the increased hydrogen bonding between hydroxyl groups at lower degrees of acetylation. The water uptake of cellulose acetate membranes was also greater at lower degrees of acetylation, further reflecting the greater hydrogen bonding with more hydroxyl groups.

Table 1

The permeability of the membranes under dry conditions is comparable to that reported in the literature [7, 9] (Table 2). CDA is slightly less permeable than CTA, due to its greater density (Table 1). The methane permeabilities are slightly lower in the presence of carbon dioxide, due to competitive sorption from this more condensable gas.

The WAXD results (Figure 2) show a bimodal distribution of d-spacings with peaks at 4.7-5.2 $\AA$ and $9.3-9.6 \AA$ and a slight shoulder at $\sim 4 \AA$. Given the kinetic diameters of $\mathrm{CO}_{2}$ and $\mathrm{CH}_{4}$ are 3.3 and $3.8 \AA$ respectively [37] it is likely that it is indeed the small shoulder that is responsible for the high $\mathrm{CO}_{2} / \mathrm{CH}_{4}$ selectivity observed for these materials. After a deconvolution of the XRD profiles, the broad peak at around $18^{\circ}$ (4.7-5.2 $\AA$ ) was assigned to the amorphous region, while the remaining peaks (at around $8.5^{\circ}$ and $21^{\circ}$ ) were regarded as the crystalline contribution [33]. The crystallinity of the CDA and CTA films were thus estimated to be $34 \pm 2 \%$ and $58 \pm 1 \%$, respectively. These values are in good agreement with the crystallinities reported by Puleo and Paul [9]. As the acetylation degree increases, the level of crystallinity increases, owing to a higher structural regularity in the membrane matrix [38]. The average d-spacings also become slightly larger, consistent with the density and FFV data discussed above. However, within experimental error, no change in crystallinity was observed upon wetting the samples. In addition, the XRD profiles show no apparent peak shift between the dry and wet samples. 
Table 2

Estimates of the mean size of the free volume elements using PALS for both cellulose acetate samples are shown in Figure $3 a$ as a function of both vapor partial pressure and water vapour activity. The average size of the free volume elements (5.8 to $6.1 \AA$ ) is in the same order of magnitude as the d-spacing values extracted from the WAXD results. The free volume element size is larger for CTA than CDA, which is consistent with the FFV data (Table 1) and the $d$-spacings identified from the XRD patterns (Figure 2). For both polymers, the average pore diameter decreases until a vapor partial pressures of $\sim 2.5 \mathrm{kPa}$ is reached, reflecting the filling of these elements with water. However, the average free volume element size increases at greater vapor partial pressures, indicating that membrane swelling is dominant. The increase in the average pore diameter appears more significant in CDA than that in CTA. This may relate to the higher hydrophilicity of CDA due to its greater number of hydroxyl groups, which allows it to more readily form hydrogen bonds with the water added to the system. On the other hand, the greater crystallinity in CTA may impose a greater restriction on the change in the free volume element size [38]. Overall, the net change in pore diameter between the dry and the wet state is small (from $6.0-6.1 \AA$ when dry to $5.9 \AA$ at $95 \%$ humidity), which may explain why the change is not clear from the WAXD results.

The relative concentration (I3) of free volume elements for both polymers reduces with increased vapor activity (Figure $3 b$ ) which suggests that the relative number of free volume elements is reducing as water fills these elements.

Figure 3

\subsection{Permeation in humid conditions}

In our prior work with polyimides, the permeability of water and gases in a humid gas stream has typically taken 2-3 hours to reach equilibrium at each water vapour activity [15]. In the present work, a similar period of time was required for the CTA and CDA membranes to reach equilibrium with gases of water vapour activity up to $\sim 0.8$. However, at water activities greater than 0.8 , permeabilities continued to change even after 8 hours (Figure 4). These continuing increases in permeability reflect the slow kinetics of membrane swelling $[39,40]$. These results are consistent with the PALS results in Figure 3 which also show membrane swelling.The extent of swelling is clearly greater for CDA, again consistent with the PALS data 
and reflecting the greater density of hydroxyl groups in this polymer. In spite of the dramatic increases in vapour and gas permeabilities, the deterioration in membrane selectivity is relatively small after the first hour, particularly for CTA.

While these results infer that ideally, all experiments should be conducted over extended periods, for practical reasons, the remaining data in this paper is presented after equilibration for two hours. However, it should be noted that this means that permeability data for water activities greater than 0.8 is underestimated relative to the long time frame result, particularly for CDA.

Figure 4

The resulting water vapor permeabilities of CTA and CDA over a range of water activities is shown in Figure 5. The absolute values are of the same order of magnitude as previously published [6, 8]. In general, CDA and CTA exhibit similar increasing trends for water permeabilities below 0.45 vapor activity (equivalent to $\sim 2.5 \mathrm{kPa}$ partial pressure). Pore filling by water molecules or clusters was confirmed by the PALS measurements (Figure 3b) for vapor partial pressures below $2.5 \mathrm{kPa}$. These clusters are known to reduce penetrant diffusivity by blocking the diffusional pathway [41]. Thus, the trend of increasing water vapor permeability for both polymers can be attributed to a combination of increasing vapor solubility and decreasing vapor diffusivity as water vapor activity increases.

At higher vapor partial pressures $(>2.5 \mathrm{kPa})$, the increase of water permeabilities in CDA is more dramatic than that in CTA, resulting from more severe membrane swelling as observed from the trends in the size of the free volume elements (Figure 3b) and the time dependent behaviour (Figure 4a). The impact of plasticization upon CDA is much greater than that on CTA because of the greater hydroxyl group content in CDA.

With the presence of $\mathrm{CO}_{2}$, the infinite dilution water permeability increases from about 10,800 and 12,700 Barrer to around 11,000 and 13,000 Barrer for CTA and CDA respectively. The small increases of water vapor permeabilities are similar to those reported earlier for polyimide membranes [15]. These increases are most likely related to $\mathrm{CO}_{2}$-induced plasticization, as it has been shown that increases in the diffusion coefficient can still occur in glassy polymers even at these low $\mathrm{CO}_{2}$ partial pressures [11].

Figure 5

Page 8 of 16 
The change in gas permeabilities and selectivities under humid conditions, relative to that under dry feed conditions, is plotted in Figure 6. Due to a combination of both competitive sorption and hindered diffusivity between the penetrating species and the water vapor, gas permeabilities decline initially. However, consistent with the PALS results, they begin to rise after $\sim 0.45$ water vapor activity (2.5 kPa vapor partial pressure) for CTA and CDA respectively, due to the aforementioned membrane swelling effects.

In the absence of $\mathrm{CO}_{2}$, the $\mathrm{CH}_{4}$ permeabilities follow a similar trend, with the permeability in CTA less affected by swelling than in CDA. In the presence of $\mathrm{CO}_{2}$, the fall in gas permeabilities in CTA is more significant as competitive sorption is enhanced. However, the increase in permeability due to swelling is also larger, so that at $80 \%$ humidity, the data converges.

However, plasticisation remains dominant for $\mathrm{CDA}$, with the small quantity of $\mathrm{CO}_{2}$ leading to a smaller fall in $\mathrm{CH}_{4}$ permeability at low water vapor pressures. At higher water vapor pressures, the $\mathrm{CO} 2$ content results in a significantly greater $\mathrm{CH}_{4}$ permeability. The final gas permeabilities of CDA are $120 \%$ and $110 \%$ of the initial (dry) $\mathrm{CH}_{4}$ and $\mathrm{CO}_{2}$ permeabilities, compared to $84 \%$ and $92 \%$ for CTA, under a humidified feed of $10 \% \mathrm{CO}_{2} / \mathrm{CH}_{4}$.

In both cases, the $\mathrm{CO}_{2} / \mathrm{CH}_{4}$ selectivities decline, but the total change is within $10 \%$ of the initial values for both CTA and CDA.

Figure 6

\section{CONCLUSIONS}

As gas humidity increases, the permeability of water vapor also increased for CDA and CTA respectively. However, the rate of increase changed significantly at a water vapor partial pressure of $\sim 2.5 \mathrm{kPa}$. The change at this point was confirmed by PALS analysis to be due to the onset of membrane swelling effects or plasticisation. For vapor activities above 0.8 (a water partial pressure of $4.6 \mathrm{kPa}$ ), membrane swelling was severe enough to influence the gas separation performance for more than 8 hours. Gas permeabilities of $\mathrm{CH}_{4}$ and $\mathrm{CO}_{2}$ followed a similar trend, with an initial decline due to competitive sorption and hindered diffusion, followed by an increase above a water partial pressure of $2.5 \mathrm{kPa}$ due to the membrane swelling. However, these changes had less impact on $\mathrm{CO}_{2} / \mathrm{CH}_{4}$ selectivity, with this value remaining within $90 \%$ of the initial condition. It should be noted that in commercial separation processes, the dense CA layer is thinner than in these experiments, less than 0.5 micron. Thinner membranes are known to swell more readily [42] and hence the changes 
observed here may occur more rapidly and at lower water partial pressures in industrial practice.

Importantly, the impact of membrane swelling, upon cellulose diacetate was found to be much greater than that in cellulose triacetate because of the greater hydroxyl group content. This suggests that the use of a highly acetylated polymer will lead to relatively stable performance in a natural gas sweetening operation. Water partial pressures below the onset of plasticisation could be readily tolerated within such an operation for extended periods.

It should also be noted that the permeability data in this work was collected at the relatively low total pressure of $7.5 \mathrm{Bar}$. In commercial natural gas separation processes, the total pressure can be ten times this value [43]. At these higher pressures, methane hydrates can also form in humid gas streams, which can further complicate the separation process and cause downstream pipe blockage.

\section{ACKNOWLEDGEMENTS}

The authors would like to thank the Particulate Fluids Processing Centre (PFPC), a Special Research Centre of the Australian Research Council for access to equipment. Funding for this project is provided by the Australian Government through its $\mathrm{CRC}$ program. $\mathrm{CMD}$ and $\mathrm{AJH}$ acknowledge the support of CSIRO's Office of the Chief Executive Science Leader program and CMD would like to acknowledge the ARC DECRA support (DE140101359). The authors would also like to thank Daicel Corporation, Japan for providing the cellulose acetate polymers for this work. Mr Hiep Lu assisted with the membrane density measurements and this assistance is gratefully acknowledged. 


\section{REFERENCES}

[1] BP Statistical Review of World Energy, in: B. p.l.c. (Ed.), 2014.

[2] R.W. Baker, K. Lokhandwala, Natural Gas Processing with Membranes: An Overview, Industrial \& Engineering Chemistry Research, 47 (2008) 2109-2121.

[3] D. Dortmundt, K. Doshi, Recent developments in CO2 removal membrane technology, UOP LLC, (1999).

[4] R.W. Baker, K. Lokhandwala, Natural Gas Processing with Membranes: An Overview, Ind. Eng. Chem. Res., 47 (2008) 2109-2121.

[5] E. Funk, S. Kulkarni, A. Swamikannu, Effect of impurities on cellulose acetate membrane performance, in: Recent Adv. in Separation Tech. AIChE Symposium Series, 1986.

[6] C.Y. Pan, C.D. Jensen, C. Bielech, H.W. Habgood, Permeation of water vapor through cellulose triacetate membranes in hollow fiber form, Journal of Applied Polymer Science, 22 (1978) 2307-2323.

[7] G.T. Paulson, A.B. Clinch, F.P. McCandless, The effects of water vapor on the separation of methane and carbon dioxide by gas permeation through polymeric membranes, Journal of Membrane Science, 14 (1983) 129-137.

[8] M. Kawaguchi, T. Taniguchi, K. Tochigi, A. Takizawa, Permeability of water and water vapor through cellulosic membranes, Journal of Applied Polymer Science, 19 (1975) 2515-2527.

[9] A.C. Puleo, D.R. Paul, S.S. Kelley, The effect of degree of acetylation on gas sorption and transport behavior in cellulose acetate, Journal of Membrane Science, 47 (1989) 301-332.

[10] M. Modesti, C. Dall'Acqua, A. Lorenzetti, E. Florian, Mathematical model and experimental validation of water cluster influence upon vapour permeation through hydrophilic dense membrane, Journal of Membrane Science, 229 (2004) 211-223.

[11] X. Duthie, S. Kentish, C. Powell, K. Nagai, G. Qiao, G. Stevens, Operating temperature effects on the plasticization of polyimide gas separation membranes, Journal of Membrane Science, 294 (2007) 40-49.

[12] K.A. Schult, D.R. Paul, Water sorption and transport in a series of polysulfones, Journal of Polymer Science Part B: Polymer Physics, 34 (1996) 2805-2817.

[13] R.T. Chern, W.J. Koros, E.S. Sanders, R. Yui, "Second component" effects in sorption and permeation of gases in glassy polymers, Journal of Membrane Science, 15 (1983) 157-169.

[14] K. Tanaka, M.N. Islam, M. Kido, H. Kita, K.-i. Okamoto, Gas permeation and separation properties of sulfonated polyimide membranes, Polymer, 47 (2006) 4370-4377.

[15] G.Q. Chen, C.A. Scholes, G.G. Qiao, S.E. Kentish, Water vapor permeation in polyimide membranes, Journal of Membrane Science, 379 (2011) 479-487.

[16] J.E. Robertson, T.C. Ward, A.J. Hill, Thermal, mechanical, physical, and transport properties of blends of novel oligomer and thermoplastic polysulfone, Polymer, 41 (2000) 6251-6262.

[17] W. Xie, H. Ju, G.M. Geise, B.D. Freeman, J.I. Mardel, A.J. Hill, J.E. McGrath, Effect of Free Volume on Water and Salt Transport Properties in Directly Copolymerized Disulfonated Poly(arylene ether sulfone) Random Copolymers, Macromolecules, 44 (2011) 4428-4438.

[18] S.J. Metz, W.J.C.v.d. Ven, M.H.V. Mulder, M. Wessling, Mixed gas water vapor/N2 transport in poly(ethylene oxide) poly(butylene terephthalate) block copolymers, Journal of Membrane Science, 266 (2005) 51-61.

[19] V. Detallante, D. Langevin, C. Chappey, M. Métayer, R. Mercier, M. Pinéri, Kinetics of water vapor sorption in sulfonated polyimide membranes, Desalination, 148 (2002) 333-339.

[20] W.P. Hsu, R.J. Li, A.S. Myerson, T.K. Kwei, Sorption and diffusion of water vapour in hydrogen-bonded polymer blends, Polymer, 34 (1993) 597-603.

[21] A. Takizawa, T. Kinoshita, M. Sasaki, Y. Tsujita, Solubility and diffusion of binary water-methyl alcohol vapor mixtures in cellulose acetate membranes, Journal of Membrane Science, 6 (1980) 265-269.

[22] E. Favre, P. Schaetzel, Q.T. Nguygen, R. Clément, J. Néel, Sorption, diffusion and vapor permeation of various penetrants through dense poly(dimethylsiloxane) membranes: a transport analysis, Journal of Membrane Science, 92 (1994) 169-184.

[23] F. Debeaufort, A. Voilley, P. Meares, Water vapor permeability and diffusivity through methylcellulose edible films, Journal of Membrane Science, 91 (1994) 125-133.

[24] F. Pan, J. Ma, L. Cui, Z. Jiang, Water vapor/propylene sorption and diffusion behavior in PVA-

Page 11 of 16 
P(AA-AMPS) blend membranes by GCMC and MD simulation, Chemical Engineering Science, 64 (2009) 5192-5197.

[25] T. Watari, H. Wang, K. Kuwahara, K. Tanaka, H. Kita, K.-i. Okamoto, Water vapor sorption and diffusion properties of sulfonated polyimide membranes, Journal of Membrane Science, 219 (2003) 137-147.

[26] J. Potreck, K. Nijmeijer, T. Kosinski, M. Wessling, Mixed water vapor/gas transport through the rubbery polymer PEBAX ${ }^{\circledR}$ 1074, Journal of Membrane Science, 338 (2009) 11-16.

[27] S. Despond, E. Espuche, A. Domard, Water sorption and permeation in chitosan films: Relation between gas permeability and relative humidity, Journal of Polymer Science Part B: Polymer Physics, 39 (2001) 3114-3127.

[28] S.J. Lue, C.L. Tsai, D.-T. Lee, K.P.O. Mahesh, M.Y. Hua, C.-C. Hu, Y.C. Jean, K.-R. Lee, J.-Y. Lai, Sorption, diffusion, and perm-selectivity of toluene vapor/nitrogen mixtures through polydimethylsiloxane membranes with two cross-linker densities, Journal of Membrane Science, 349 (2010) 321-332.

[29] M.D. Zipper, A.J. Hill, Application of positron annihilation lifetime spectroscopy to the study of glassy and partially crystalline materials, Metals forum, 18 (1994) 215-233.

[30] S.L. Liu, R. Wang, T.S. Chung, M.L. Chng, Y. Liu, R.H. Vora, Effect of diamine composition on the gas transport properties in 6FDA-durene/3,3'-diaminodiphenyl sulfone copolyimides, Journal of Membrane Science, 202 (2002) 165-176.

[31] ASTM, Standard Test Methods for Density and Specific Gravity (Relative Density) of Plastics by Displacement, in, ASTM International: West Conshohocken, 1993.

[32] S.S. Hosseini, M.M. Teoh, T.S. Chung, Hydrogen separation and purification in membranes of miscible polymer blends with interpenetration networks, Polymer, 49 (2008) 1594-1603.

[33] S. Park, J.O. Baker, M.E. Himmel, P.A. Parilla, D.K. Johnson, Cellulose crystallinity index: measurement techniques and their impact on interpreting cellulase performance, Biotechnology for Biofuels, 3 (2010) 10-10.

[34] T.L. Dull, W.E. Frieze, D.W. Gidley, J.N. Sun, A.F. Yee, Determination of Pore Size in Mesoporous Thin Films from the Annihilation Lifetime of Positronium, The Journal of Physical Chemistry B, 105 (2001) 4657-4662.

[35] G.Q. Chen, C.A. Scholes, C.M. Doherty, A.J. Hill, G.G. Qiao, S.E. Kentish, The thickness dependence of Matrimid films in water vapor permeation, Chemical Engineering Journal, 209 (2012) 301-312.

[36] J. Kansy, Microcomputer program for analysis of positron annihilation lifetime spectra, Nuclear Instruments and Methods in Physics Research Section A: Accelerators, Spectrometers, Detectors and Associated Equipment, 374 (1996) 235-244.

[37] D.W. Breck, Zeolite Molecular Sieves, in, John Wiley \& Sons, New York, 1973.

[38] S. Cao, Y. Shi, G. Chen, Influence of acetylation degree of cellulose acetate on pervaporation properties for MeOH/MTBE mixture, Journal of Membrane Science, 165 (2000) 89-97.

[39] M. Sanopoulou, J.H. Petropoulos, Sorption and longitudinal swelling kinetic behaviour in the system cellulose acetate-methanol, Polymer, 38 (1997) 5761-5768.

[40] M. Sanopoulou, P.P. Roussis, J.H. Petropoulos, A detailed study of the viscoelastic nature of vapor sorption and transport in a cellulosic polymer. II. Sorption and longitudinal swelling kinetic correlations, J. Polym. Sci., Part B: Polym. Phys., 33 (1995) 2125-2136.

[41] G.Q. Chen, C.A. Scholes, C.M. Doherty, A.J. Hill, G.G. Qiao, S.E. Kentish, Modeling of the sorption and transport properties of water vapor in polyimide membranes, Journal of Membrane Science, 409 (2012) 96-104.

[42] C.A. Scholes, G.Q. Chen, G.W. Stevens, S.E. Kentish, Plasticization of ultra-thin polysulfone membranes by carbon dioxide, Journal of Membrane Science, 346 (2010) 208-214.

[43] R.W. Baker, Membrane technology and applications, J. Wiley, 2004. 


\section{Tables}

Table 1: The physical properties of cellulose diacetate (CDA) and cellulose triacetate (CTA)

Table 2: The $\mathrm{CO}_{2}$ and $\mathrm{CH}_{4}$ permeability $(\mathrm{P})$ and the $\mathrm{CO}_{2} / \mathrm{CH}_{4}$ selectivity $(\alpha)$ for CDA and CTA films under dry conditions at 7.5 bar total pressure and $35^{\circ} \mathrm{C}$. 
Table 1

\begin{tabular}{|c|c|c|c|c|}
\hline Polymer & $\begin{array}{c}\text { Acetylation } \\
\text { degree }^{(a)} \\
(\%)\end{array}$ & $\begin{array}{l}\text { Density } \\
\left(\mathrm{g} / \mathrm{cm}^{3}\right)\end{array}$ & $\begin{array}{l}\text { Fractional free } \\
\text { volume (FFV) }\end{array}$ & $\begin{array}{c}\text { Water uptake } \\
\text { at } 35^{\circ} \mathrm{C} \\
\text { (wt\%) }\end{array}$ \\
\hline Cellulose diacetate (CDA) & 51.6 & 1.335 & 0.147 & 18.8 \\
\hline Cellulose triacetate (CTA) & 61.6 & 1.299 & 0.157 & 8.8 \\
\hline
\end{tabular}

Table 2

\begin{tabular}{|c|c|c|c|c|}
\hline \multirow[t]{3}{*}{ Polymer } & \multirow{3}{*}{$\begin{array}{c}\text { Pure } \mathrm{CH}_{4} \\
\mathrm{P}\left(\mathrm{CH}_{4}\right) \\
\text { Barrer }\end{array}$} & \multicolumn{3}{|c|}{$10 \% \mathrm{CO}_{2}$ in $\mathrm{CH}_{4}$} \\
\hline & & $\mathrm{P}\left(\mathrm{CH}_{4}\right)$ & $\mathrm{P}\left(\mathrm{CO}_{2}\right)$ & $\alpha\left(\mathrm{CO}_{2} / \mathrm{CH}_{4}\right)$ \\
\hline & & Barrer & Barrer & - \\
\hline Cellulose diacetate (CDA) & 0.259 & 0.204 & 6.15 & 30.4 \\
\hline Cellulose triacetate (CTA) & 0.272 & 0.256 & 6.51 & 25.4 \\
\hline
\end{tabular}




\section{Figure Captions}

Figure 1: Chemical structure of cellulose acetate.

Figure 2: XRD patterns of CTA and CDA (dry and wetted states).

Figure 3: (a) Intensity of oPs (I3) and (b) microvoid diameters over the range of vapor partial pressures obtained from PALS measurements for CTA and CDA at $25^{\circ} \mathrm{C}$.

Figure 4: Changes in the permeabilities of water (a), $\mathrm{CH}_{4}(\mathrm{~b})$ and $\mathrm{CO}_{2}(\mathrm{c})$ and the $\mathrm{CO}_{2} / \mathrm{CH}_{4}$ selectivity (d) as time progresses for CTA and CDA under humid conditions $\left(10 \% \mathrm{CH}_{4} / \mathrm{CO}_{2}\right.$, 0.8 and 0.88 vapor activities) at $35^{\circ} \mathrm{C}$ and 7.5 bar. The ratios are based on the water vapor permeability at 120 min under 0.8 vapor activity.

Figure 5: Water vapor permeability of CTA and CDA under humidified gas conditions $\left(\mathrm{CH}_{4}\right.$ and $\left.10 \% \mathrm{CH}_{4} / \mathrm{CO}_{2}\right)$ at $35^{\circ} \mathrm{C}, 7.5$ bar.

Figure 6: Ratio of the initial gas permeability and $\mathrm{CO}_{2} / \mathrm{CH}_{4}$ selectivity of CTA and CDA ((a) and (b) respectively) under 7.5 bar humidified feed at $35^{\circ} \mathrm{C}$. 


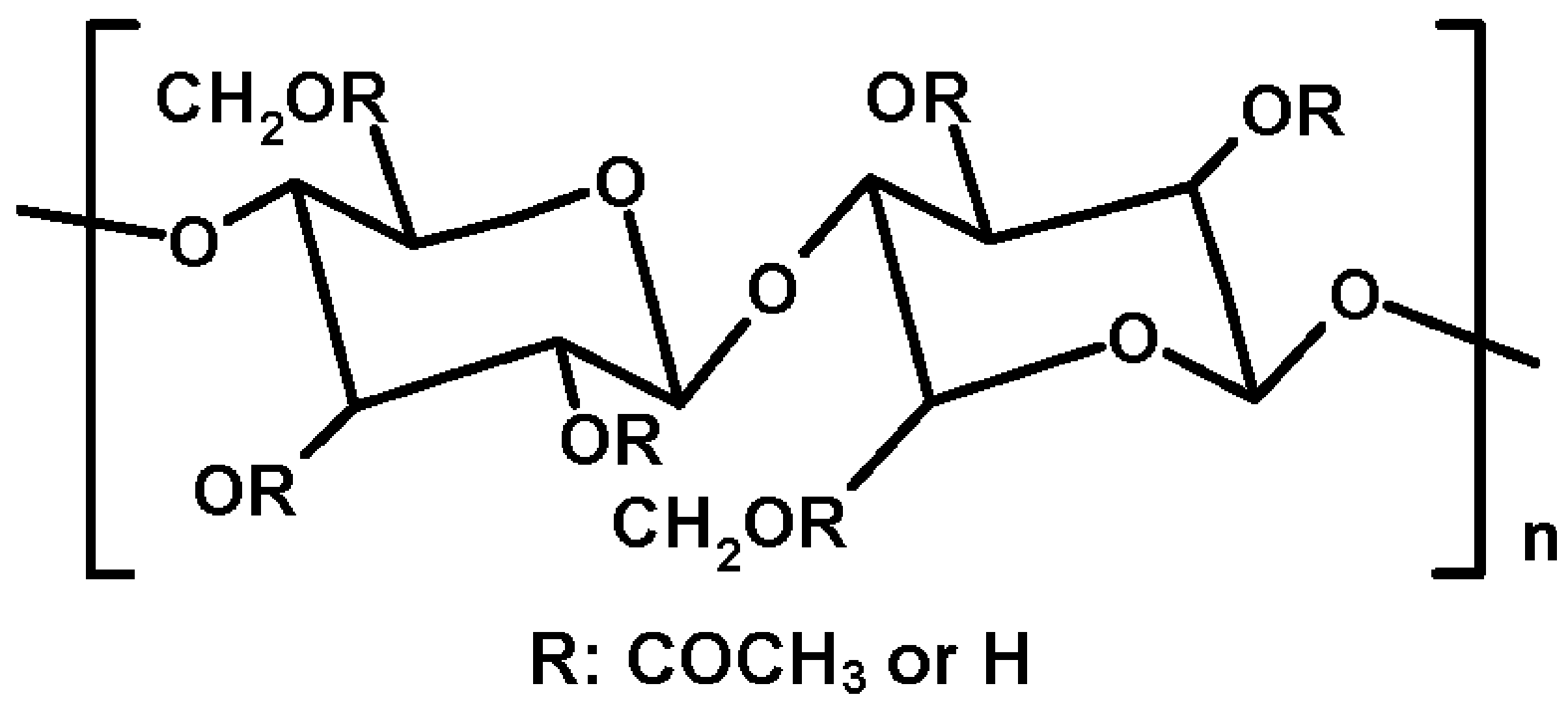




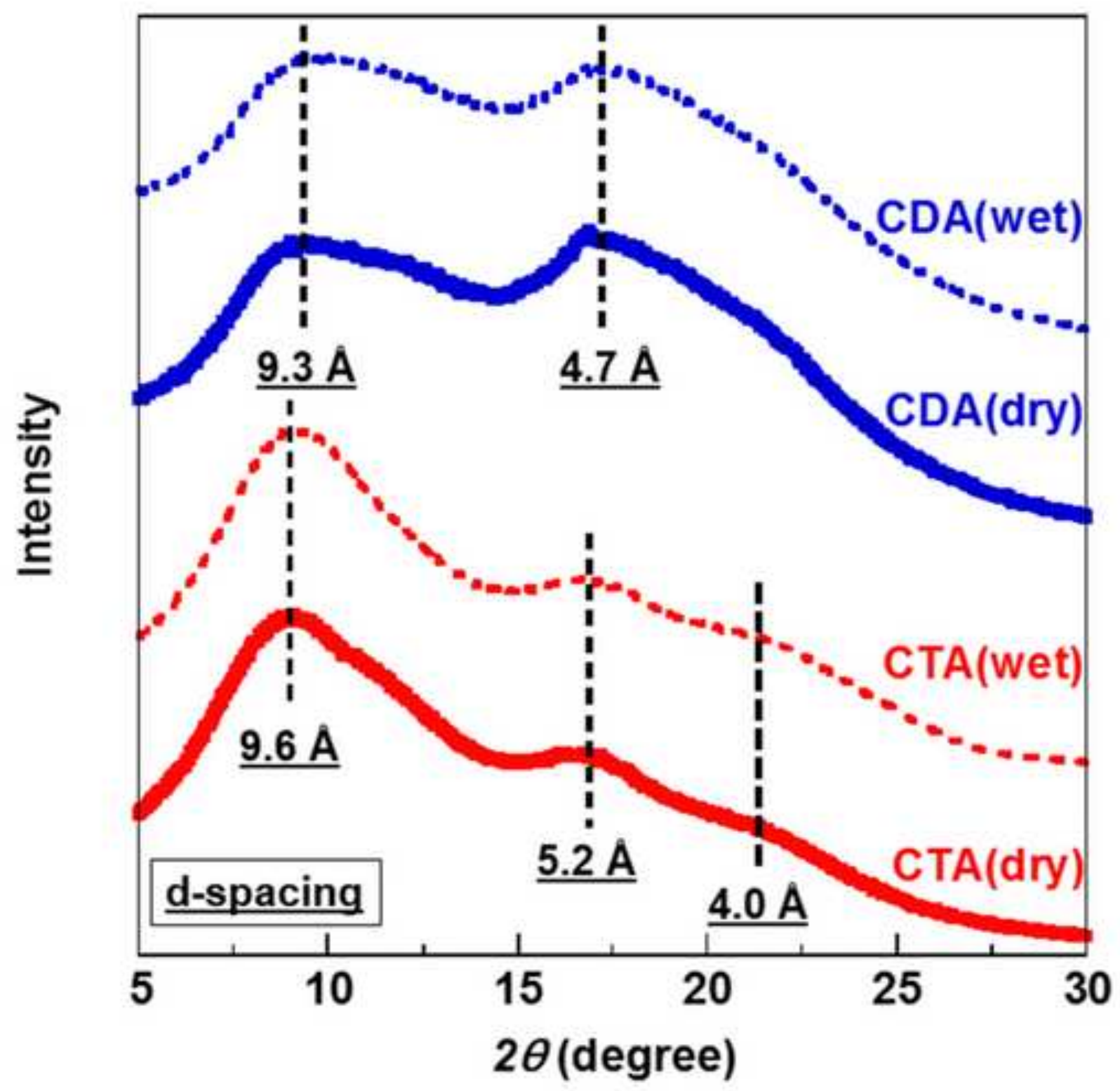




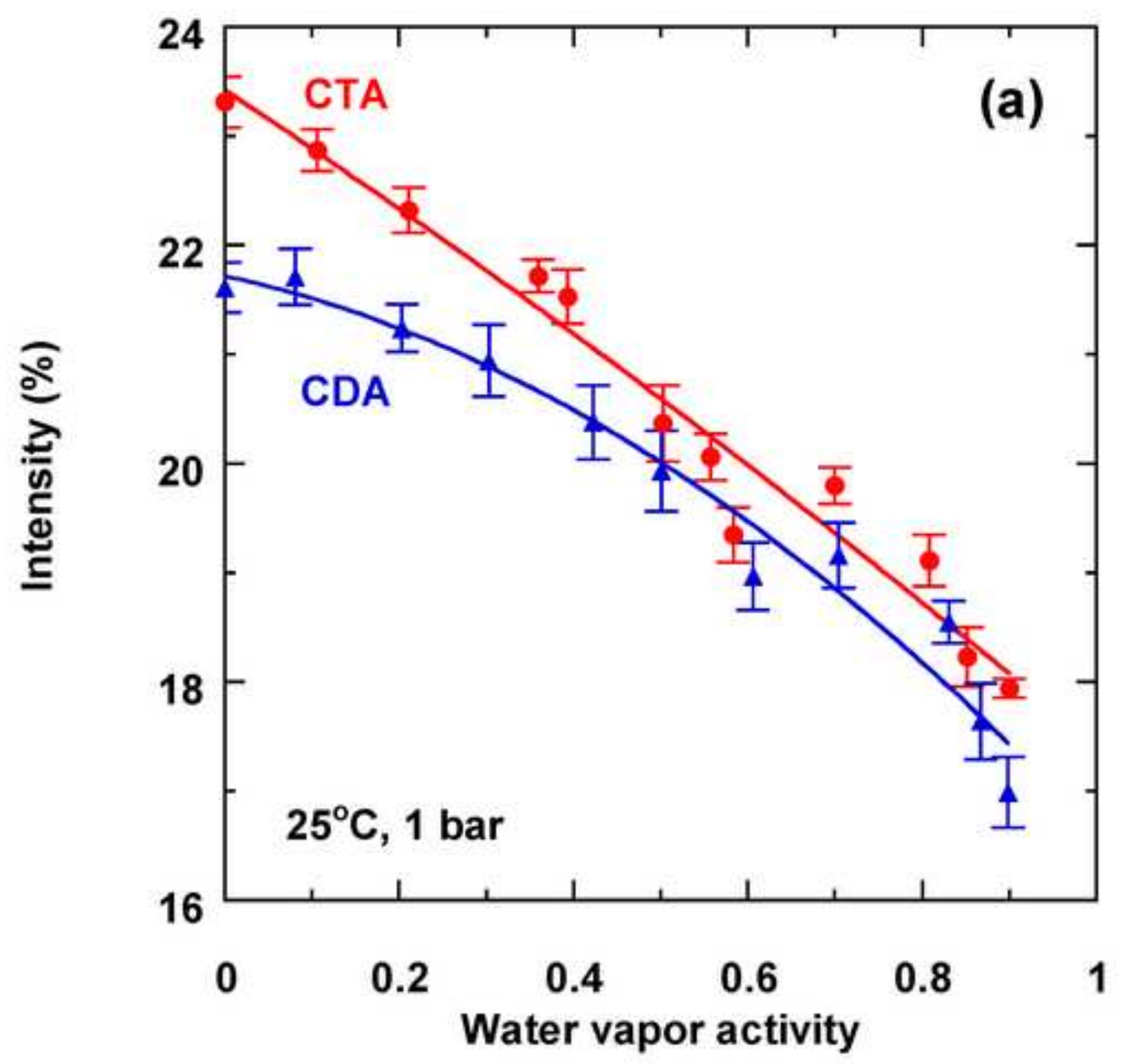




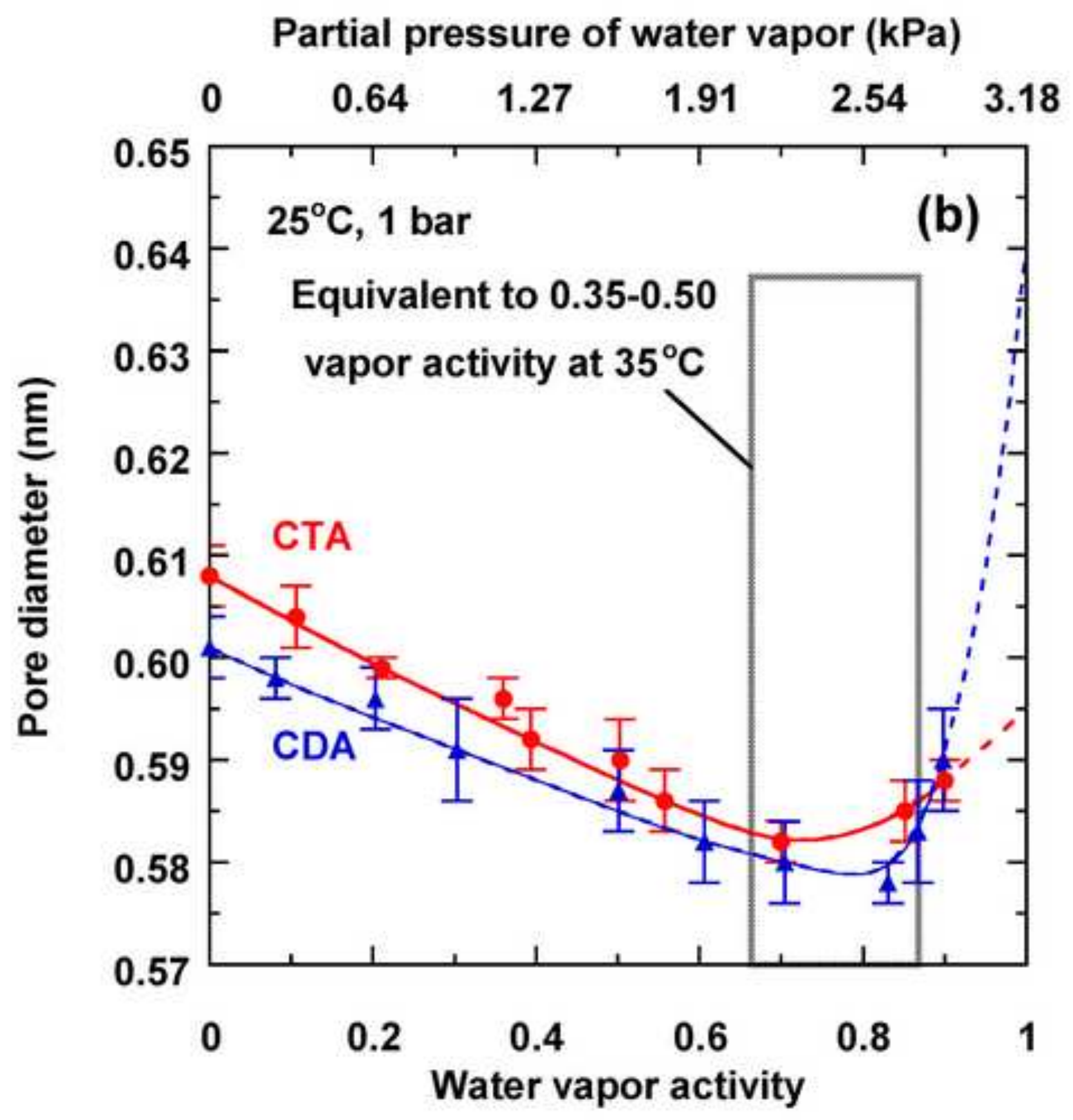




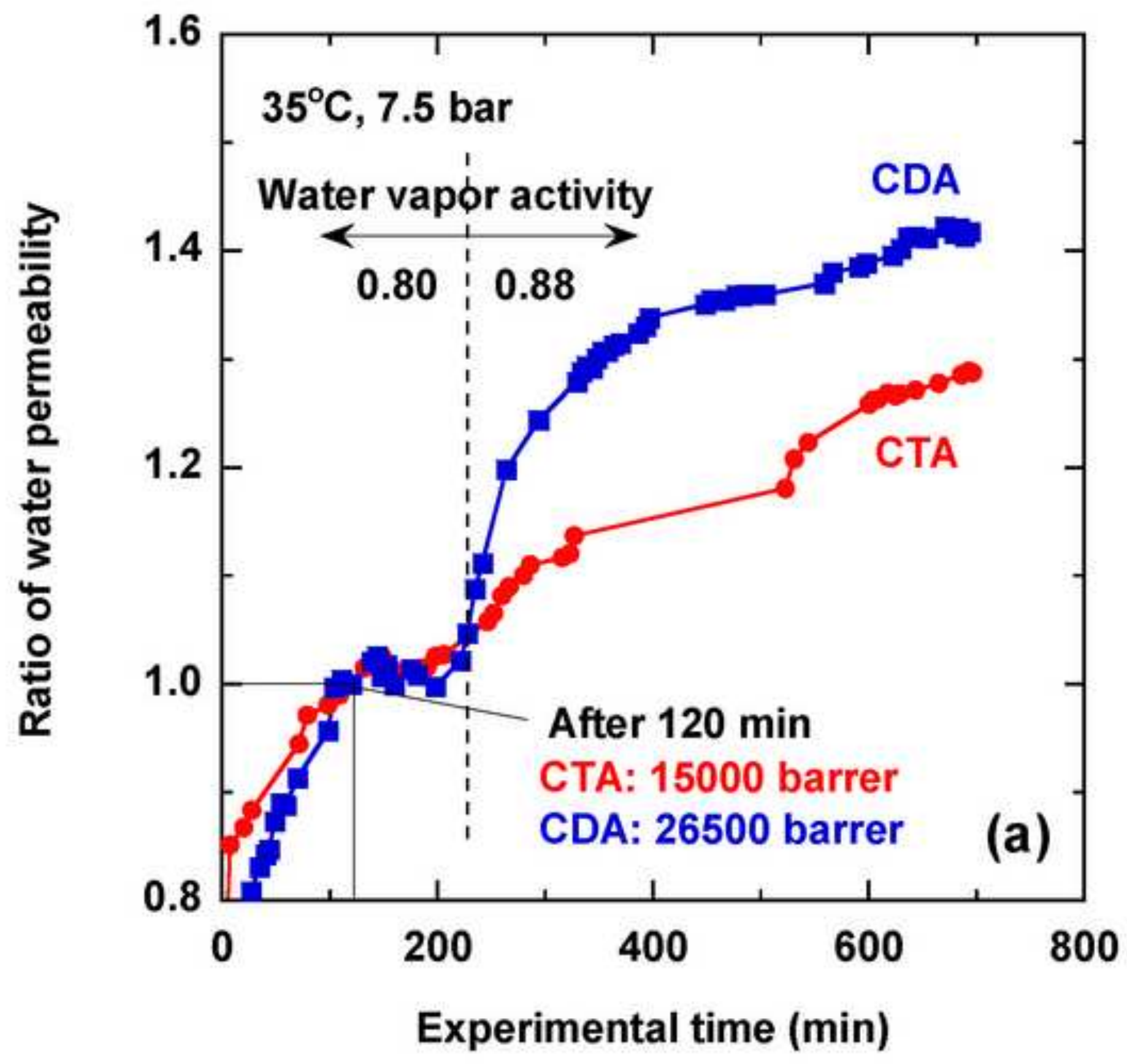




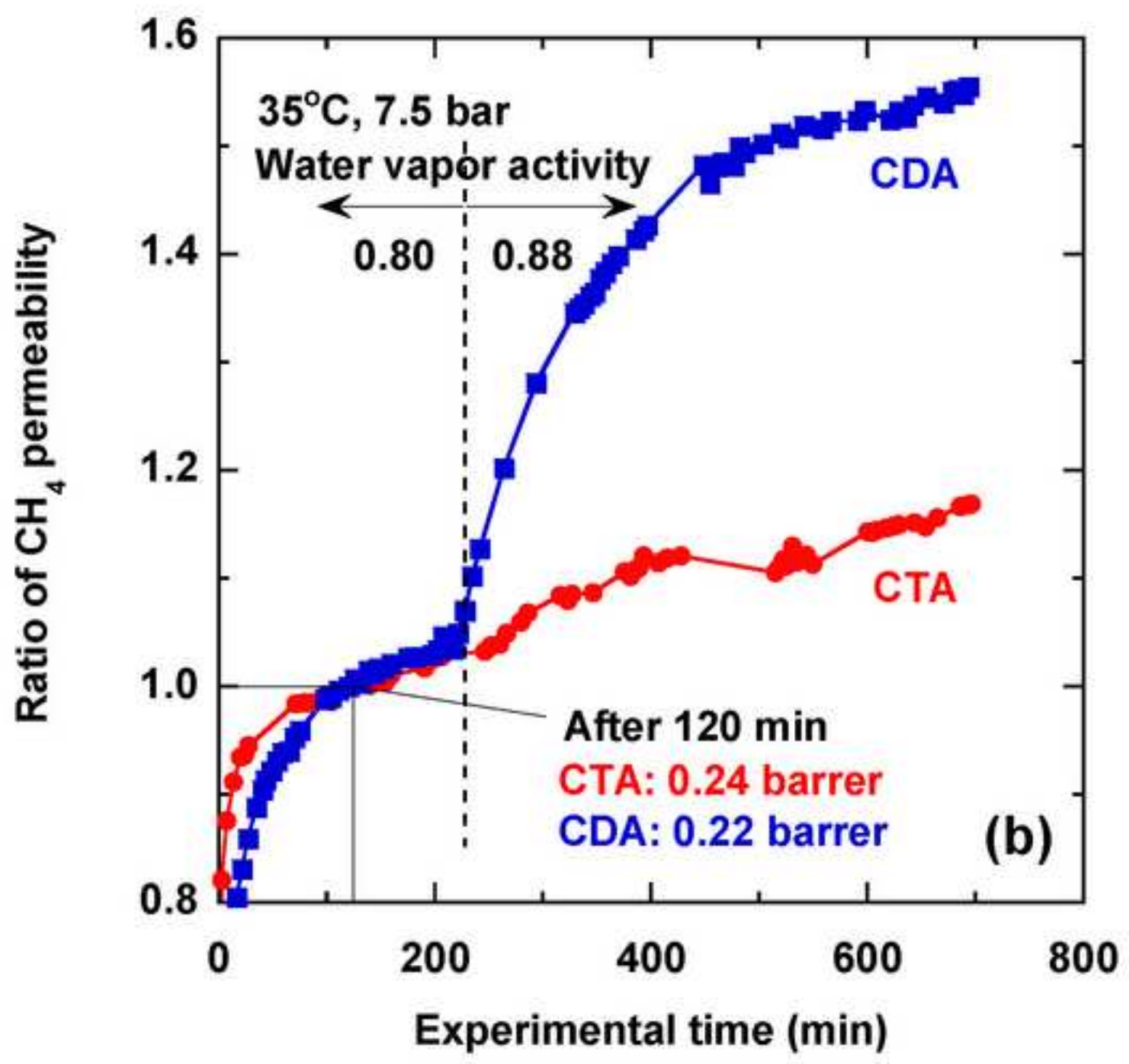




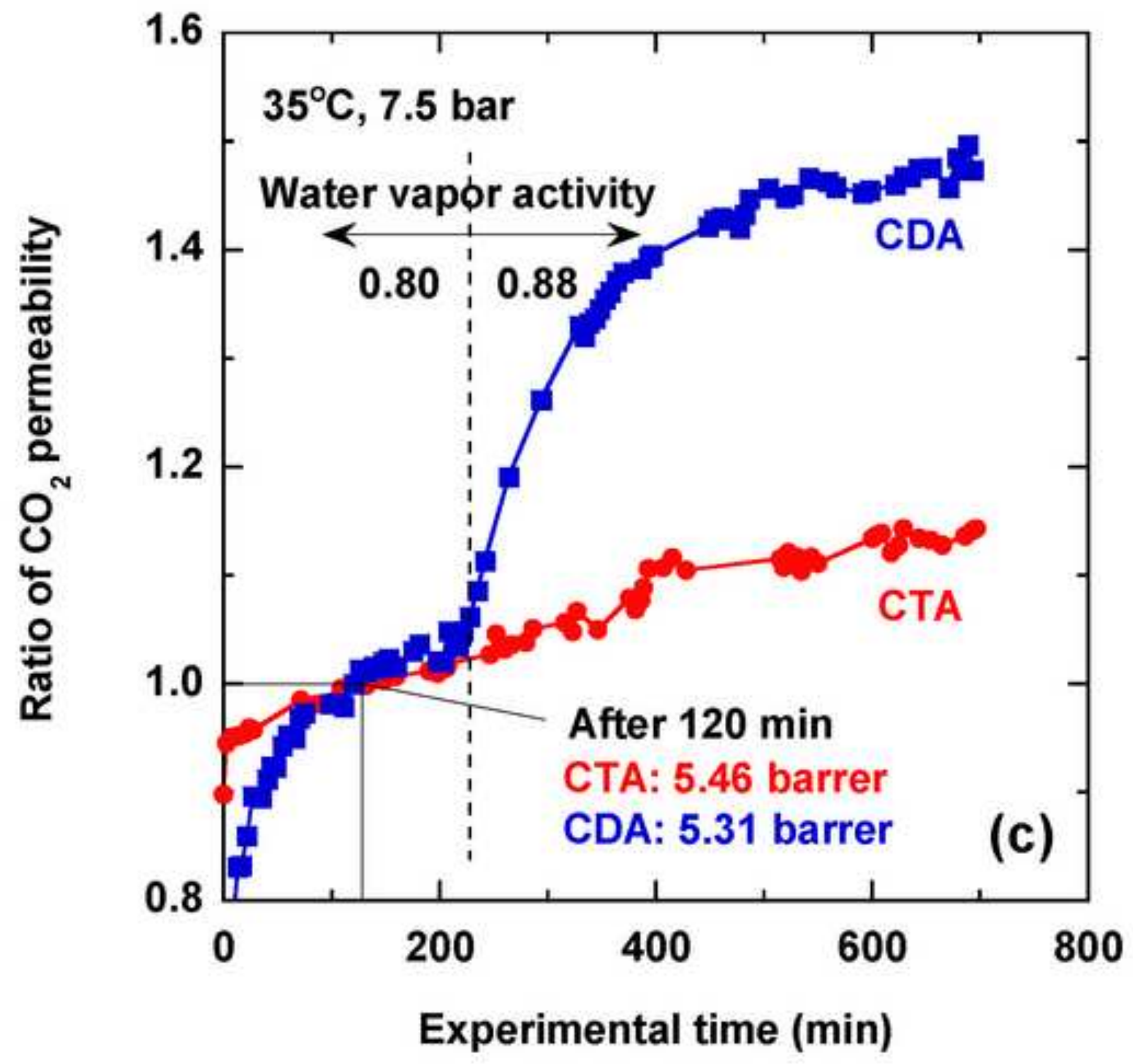




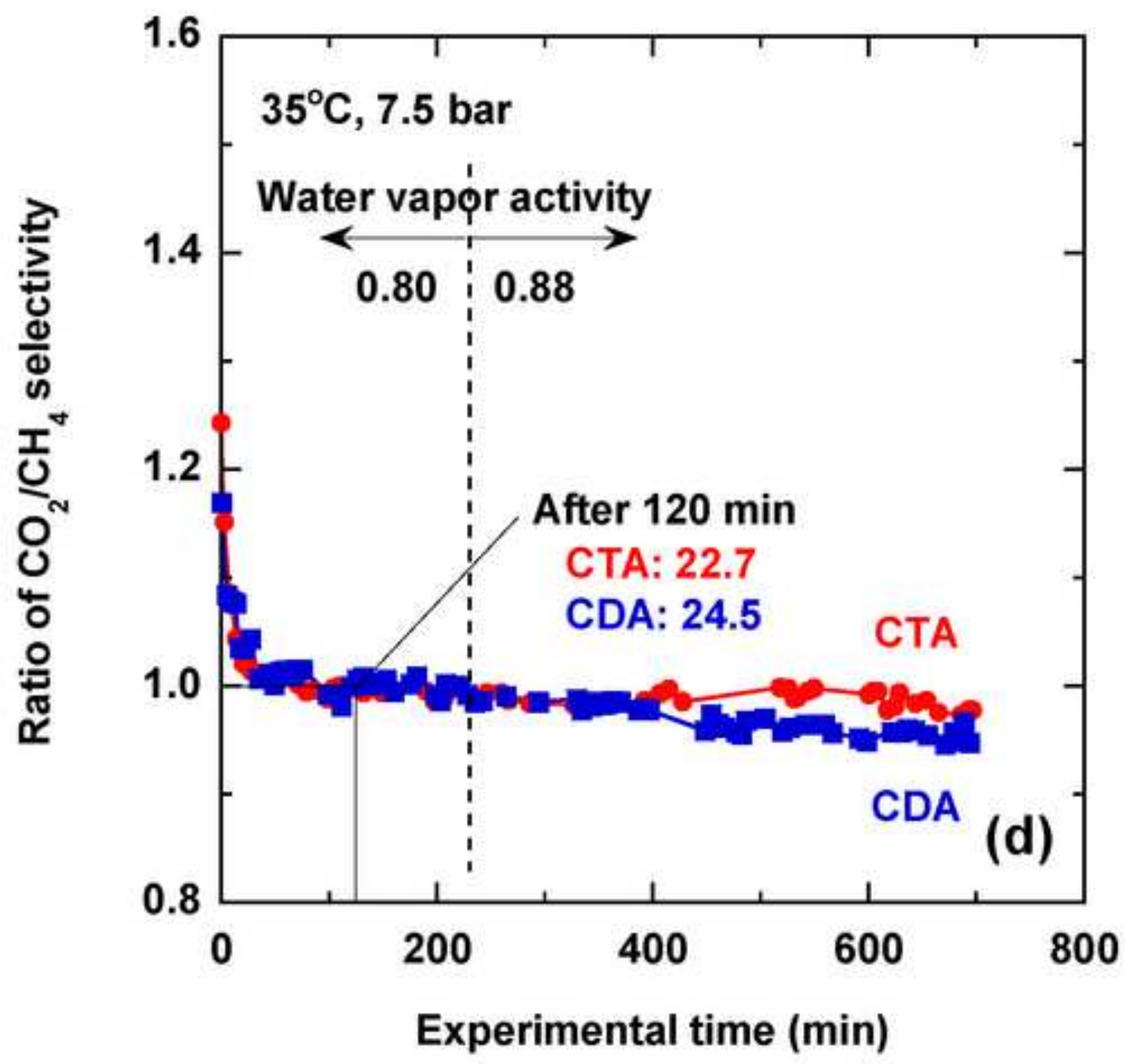




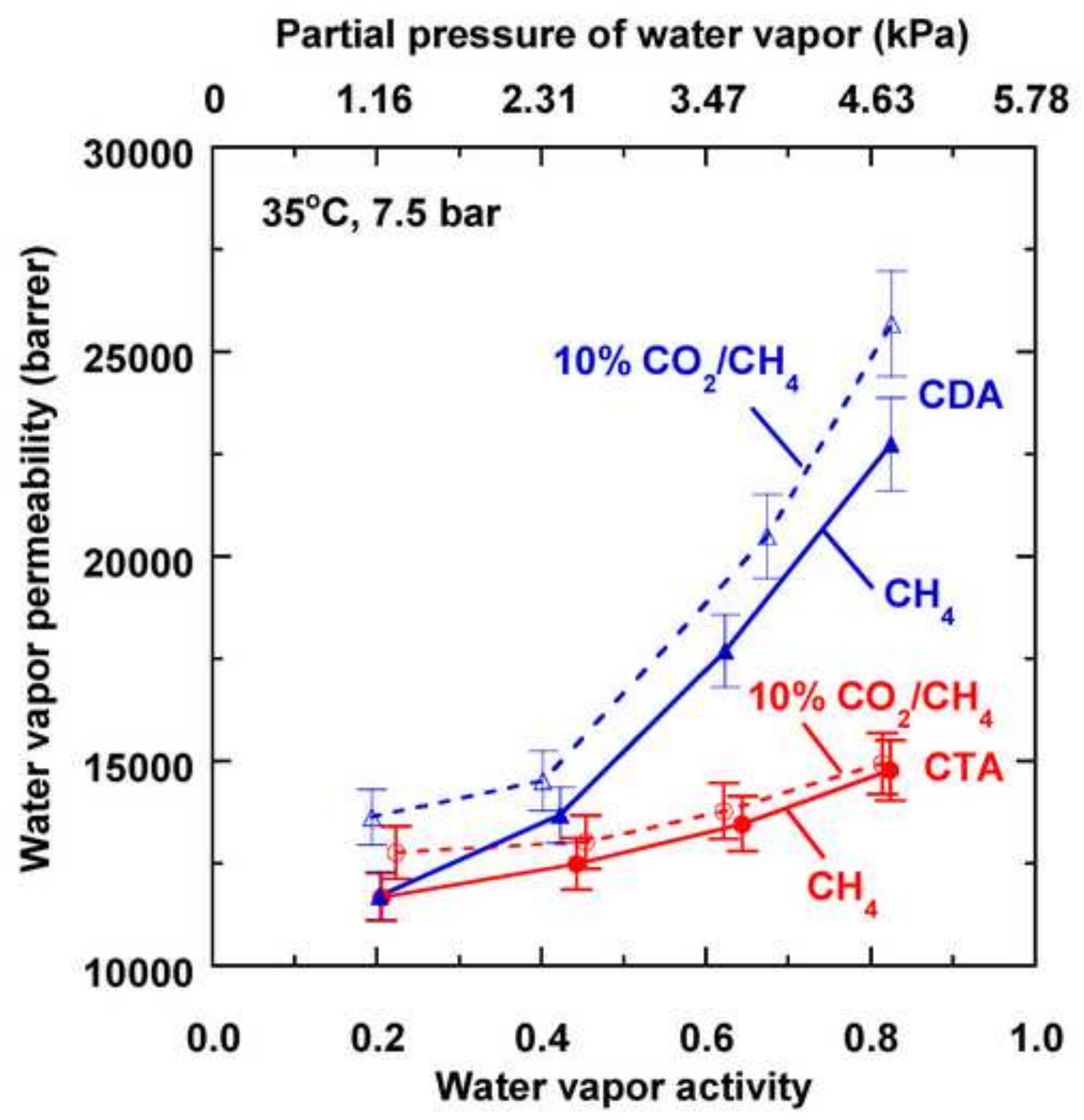

(

\subsection{7}




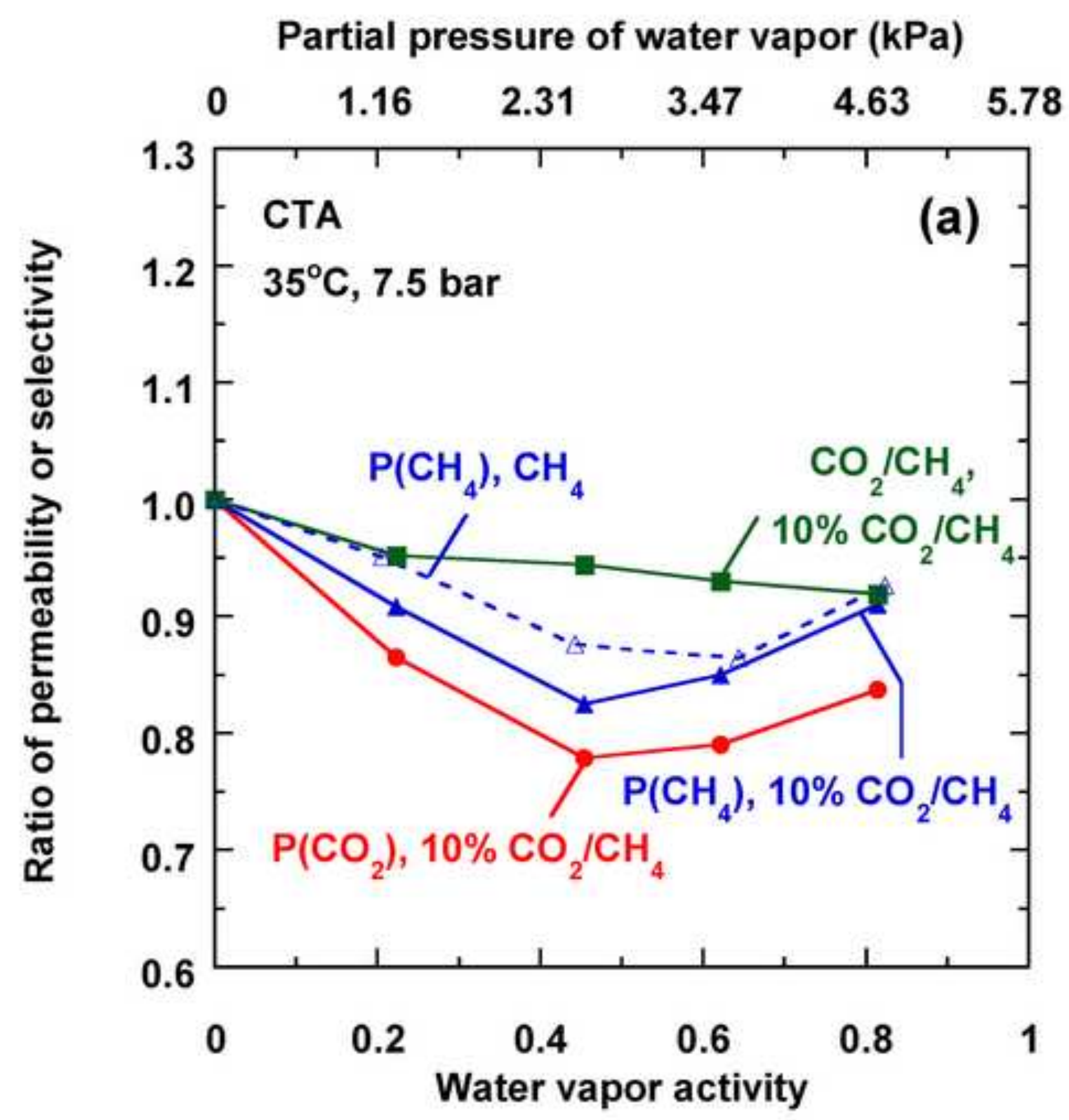


Figure $6 b$

Click here to download high resolution image

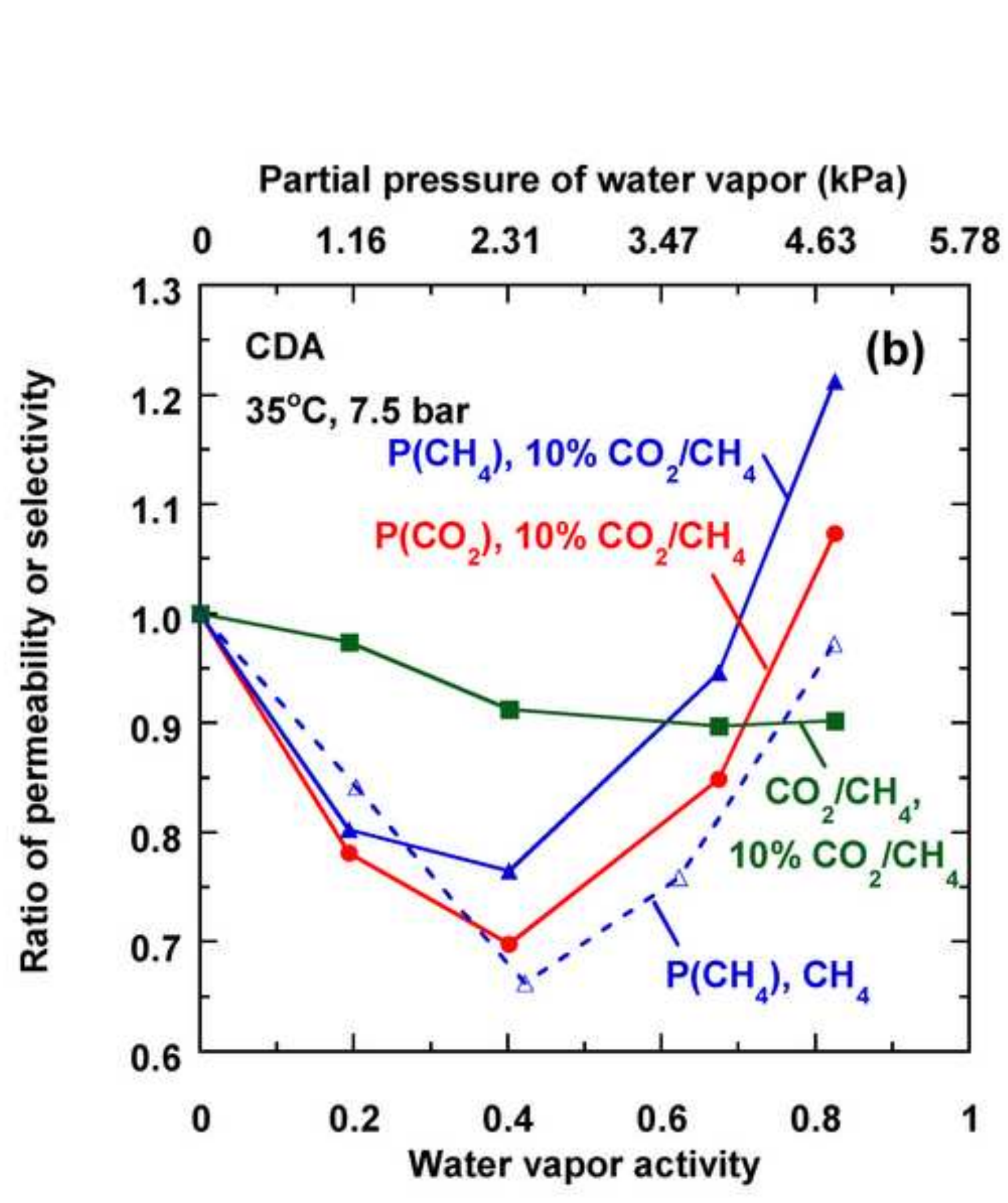

Partial pressure of water vapor (kPa) 


\section{University Library}

\section{- M M N E R VA A gateway to Melbourne's research publications}

Minerva Access is the Institutional Repository of The University of Melbourne

Author/s:

Chen, GQ;Kanehashi, S;Doherty, CM;Hill, AJ;Kentish, SE

Title:

Water vapor permeation through cellulose acetate membranes and its impact upon membrane separation performance for natural gas purification

Date:

2015-08-01

\section{Citation:}

Chen, G. Q., Kanehashi, S., Doherty, C. M., Hill, A. J. \& Kentish, S. E. (2015). Water vapor permeation through cellulose acetate membranes and its impact upon membrane separation performance for natural gas purification. Journal of Membrane Science, 487 (0), pp.249-255. https://doi.org/10.1016/j.memsci.2015.03.074.

Persistent Link:

http://hdl.handle.net/11343/55118 